\title{
Arbetet med individuella utvecklingsplaner - rektorers syn på mentorer, utvecklingssamtal och lärande
}

\section{Av Susanne Andersson, Britt-Louise Ek-Gustafsson, Maria Lindgren, Lena Willman och Linda Wågström}

\section{Inledning}

Individuella utvecklingsplaner (IUP) som ett obligatorium för grundskolan infördes den 1 juli 2006 (Grundskoleförordningen 7 kap 2 §) som en följd av att utvecklingssamtalen inte hade ett innehåll som motsvarade det som staten avsåg. I en avhandling av Johan Hofvendahl (2006) blev det tydligt att det inte var målen och hur eleven låg till kunskapsmässigt som var huvudinnehållet i utvecklingssamtalet. Istället handlade samtalen om personliga värdeomdömen och egenskaper som att eleven är pigg och glad och har en bra attityd.

Kravet på dokumentation av elevens lärande i form av en IUP skulle göra utvecklingssamtalen mer stringenta och därmed bidra till ökad måluppfyllelse för de enskilda eleverna och för skolan i ett lokalt och nationellt perspektiv. Fr.o.m. den 15 juli 2008 utökades IUP:n med skriftliga omdömen i alla ämnen (Grundskoleförordningen 7 kap 2 §). Detta var ytterligare en åtgärd som syftade till att tydliggöra skolans krav på kunskapsutveckling. Enligt Skolverket var reformen även ett led i professionalisering av lärarkåren (Högberg 2009). IUP:n ska följaktligen bli styrande för utvecklingssamtalet samtidigt som elevens kunskapsutveckling ska dokumenteras tydligt. På så vis ska eleverna få klart för sig hur de ligger till i olika ämnen och i utvecklingen av de förmågor som läroplan och kursplaner beskriver, och föräldrarna ska bli delaktiga i barnets utveckling mot målen.

IUP:n ska beskriva vilka insatser som skolan planerar att göra för att alla elever ska nå så långt som möjligt utifrån sina förutsättningar. Det gäller således inte bara de elever som har svårigheter att nå målen och för vilka dessutom åtgärdsprogram ska upprättas. Läroplanen utgår från ett sociokulturellt perspektiv som tar fasta på att elevens utvecklingssteg utgår från utvecklingszoner som får näring i det sociala samspel som de har med andra elever och vuxna i skolan. (Se nästa avsnitt 2.)

I ett stödmaterial från Skolverket har vi hämtat följande utdrag om hur IUP är tänkt att stödja elevens fortsatta lärande (Moreau och Wretman 2009 s. 2):

En individuell utvecklingsplan ska vara ett stöd för elevens fortsatta lärande. Den ska dels innehålla omdömen om elevens kunskapsutveckling, dels en planering av hur skolan ska arbeta för att eleven ska utvecklas så långt som möjligt i riktning mot de nationella målen samt vad eleven och vårdnadshavaren kan göra och ansvara för.

Det nya uppdraget handlar om att det som tidigare skulle förmedlas muntligt om elevens kunskapsutveckling nu ska finnas i skrift. 
De skriftliga omdömena ska /.../vara relaterade till hur eleven utvecklats i relation till lokala pedagogiska planeringar.

Den individuella utvecklingsplanen är tänkt att stödja och stimulera det fortsatta lärandet. De skriftliga omdömena beskriver elevens kunskapsutveckling i de ämnen, där eleven fătt undervisning.

I varje ämne där eleven har undervisning ska det skrivas ett skriftligt omdöme som beskriver elevens kunskaper i nuläget.

Omdömet ska inte utgå från elevens brister utan från vad eleven kan, men även tala om vad som ska utvecklas.

I det mål- och resultatstyrda system som skolan ingår i sedan mitten på 1990-talet spelar rektor en avgörande roll för att undervisningen genomförs så att de mål som har satts upp nås.

Rektor har därför en nyckelroll i reformarbetet. Det är rektor som tolkar reformen och ansvarar för att den sätter avtryck i klassrummet och därmed bidrar till att elever lyckas nå målen. Det är också rektor som avgör hur de skriftliga omdömena ska utformas, t.ex. om de ska vara betygsliknande och om social utveckling ska inkluderas (Grundskoleförordningen 7 kap 2 §).

\section{Sociokulturellt perspektiv på arbetet med IUP}

Liksom i Läroplan för grundskolan (Lpo 94) är de bakomliggande tankarna för arbetet med IUP sociokulturellt. Detta synsätt beskrivs av Strandberg (2008, s. 15f). Han skriver att IUP visserligen är ett skriftligt dokument men framförallt en utvecklingsinsats; eleven ska inte vara ensam i sin utveckling utan ska vara åtföljd av en vuxen lärare eller mentor som i sociokulturell anda både är medvandrare och färdledare på vägen. Strandberg menar att IUP:n är inbäddad i skolans övriga aktiviteter som han beskriver som åtta pusselbitar:

\section{Mentorskap}

Den första pusselbiten handlar om att utveckla coachningen av eleverna. Denna aktivitet utförs ofta av en mentor, och Strandberg (2008 s. 20) betonar att rektor måste säkerställa att mentorskapet fungerar och att arbetslagets fördelning av mentorsuppgifterna är rimliga.

\section{Utvecklingssamtal}

IUP:n är kopplad till utvecklingssamtal där föräldrar, elev och mentor möts med elevens måluppfyllelse i fokus. Strandberg (2008 s. 28) menar att rektorn har en viktig uppgift med att ge utvecklingssamtalet goda förutsättningar.

\section{Lärarlag}

För att fungera som mentor behöver lärare stöd i ett fungerande arbetslag med samtal om det pedagogiska arbetet och elevernas utveckling. Rektorns uppgift är att organisera sin skola i funktionella och fungerande arbetslag samt se till att det finns tid för arbetet $\mathrm{i}$ arbetslagen (2008 s. 28-31). 


\section{Progression}

Mentorns professionella säkerhet och trygghet i utvecklingssamtalet hänger samman med den kunskap mentorn har om hur skolan tänker om kunskap, bedömning och lärandets progression. Därför ska rektor se till att lärarna är medvetna om detta och att barnens och ungdomarnas lärande ses i långt perspektiv (2008 s. 31-34).

\section{Lärande}

Strandberg (2008 s. 34-39) betonar att utvecklingssamtalen ska inspirera till nya tag i skolans vardag och locka till nya steg i kunskapsutvecklingen. Han skriver att skolans vardag ska vara ett lockande träningsläger för olika slags lärandeaktiviteter och att rektor ska stödja denna kunskapsutveckling. Träningslägret byggs med hjälp av fyra sociokulturella dimensioner (Från Kan-inte till Kan, Lärandets sociala dimension, Lärandets verktygsdimension, Lärandets rumsliga dimension och Lärandets kreativa dimension) så att eleverna kan ta nya steg och agera huvudet högre än vad de gjort tidigare.

\section{Elevens reflektion}

Strandberg (2008 s. 39-40) menar att det är lätt och roligt att vara en god mentor när eleverna kommer förberedda till utvecklingssamtalen genom att ha dokumenterat sina lärprocesser och förberett frågor.

\section{Föräldraengagemang}

Om föräldrar är bekanta med de kunskapsmål som deras barn arbetar mot är det lättare för dem att engagera sig inför utvecklingssamtalen, och då kan de reda ut missförstånd och finna förnuftiga lösningar som alla är med på (2008 s. 41). Strandberg (s. 42) skriver att "det är föräldrarna som är huvudansvariga för barnets utveckling" och att skolans roll är kompletterande.

\section{Beredskap för förändring}

"Om eleven ska ta ett framåtsyftande steg, göra något hon eller han ännu inte kan, då ligger det i sakens natur att denna process underlättas om alla har en beredskap för förändring" (2008 s. 43). Elever, föräldrar, lärare, arbetslag och rektorer måste enligt Strandberg vara beredda på att ändra rutiner och arbetssätt så att kreativa problemlösningar stimuleras.

Strandberg ser således IUP som en social aktivitet och en metod för att bevaka elevernas kunskapsmässiga och sociala utveckling som alla tre parter - elev, lärare och förälder - kan påverka. Han menar också att rektorerna har viktiga roller med att skapa förutsättningar för förändringen. 


\section{Syfte och frågeställningar}

Syftet med undersökningen ${ }^{1}$ är att utröna hur det sociokulturella perspektivet från läroplanen implementerats i grundskolan och hur rektorer ser på arbetet med IUP på sina skolor.

Vi söker svar på hur rektorer ser på följande frågeställningar:

- Hur stimuleras elever av sina mentorer/lärare att gå vidare i sina utvecklingszoner?

- Hur fungerar samarbetet i utvecklingssamtalen mellan elev, lärare och föräldrar?

- Hur arbetar arbetslagen för att stödja elevernas lärande?

- Hur används kursplanemålen?

- Hur fungerar lärandeaktiviteter för eleverna?

- Hur reflekterar eleverna över lärandet?

- Hur engagerar föräldrarna sig i elevernas lärande?

- Hur beredd är skolan för förändringar som grundar sig i IUP?

\section{Metod och material}

För att få svar på ovanstående frågor har vi arbetat med ett enkätformulär hämtat ur Strandberg (2008). Formuläret är tänkt som ett verktyg för rektorerna att fă kunskap om hur medarbetarna på skolan förhåller sig till arbetet med IUP, och resultatet är tänkt att tjäna som underlag för skolutvecklingen. Det består av 60 påståenden som man ska ta ställning till genom att markera om man "instämmer helt", "instämmer men inte fullt ut", "instämmer något" eller "instämmer inte alls". Eftersom vi är intresserade av rektorernas syn har vi reviderat enkätformuläret genom att komplettera med ett femte svarsalternativ: "känner ej till". Vi trodde nämligen att rektorerna skulle ha svårt att svara på en del frågor som rör elever och föräldrar. Enkätformuläret bifogas som bilaga.

Enkäten delades ut i december 2008 till 16 rektorer i två olika kommuner. De fick enkäten i samband med möten och fick samtidigt muntlig information om den. Enkäten samlades in ett par veckor senare vid andra möten för rektorerna.

Efter påminnelser hade vi fătt in svar från 11 personer. (Svarsfrekvensen är $69 \%$ ). Det finns även ett visst internt bortfall; tre frågor (1:13, 3:6 och 5:4) besvarades av 10 personer. Det är viktigt att uppmärksamma att det endast är 11 rektorer som står bakom svaren och att vi därför inte kan dra långtgående slutsatser av resultaten. Vi menar ändå att enkätsvaren hjälper oss att förstå hur rektorer ser på arbetet med IUP ${ }^{2}$.

I tolkningen av resultatet har vi tolkat en hög grad av instämmande i påståendena som en styrka och följaktligen en lägre grad som en svaghet. Exempelvis har vi sett det som en styrka om rektorerna markerat alternativet "instämmer helt" i påståendet: Mentorskap finns, och omvänt har vi sett det som en svaghet om de markerat alternativet "instämmer inte alls". För att få en måttstock på dessa styrkor och svagheter har vi gett varje svarsalternativ ett värde så att markeringar i "instämmer helt" har fått 3 poäng, "instämmer men inte fullt ut" har fătt

1 I en forskningscirkel som pågått 2008-2009 vid Växjö universitet har deltagarna sökt svar på frågan om hur man arbetar med individuella utvecklingsplaner med skriftliga omdömen i den svenska grundskolan. Denna undersökning är en del av arbetet i forskningscirkeln.

2 Vi tänker oss att resultatet kan användas av rektorer eller rektorsgrupper att ställa egna erfarenheter mot. 
2 poäng, "instämmer något" har fått 1 poäng och "instämmer inte alls" liksom "känner inte till" har fătt 0 poäng. Dessa värden har sedan multiplicerats med antalet markeringar inom varje svarsalternativ, och medelvärdet för de olika aktiviteterna har räknats ut.

\section{Resultat}

Utifrån enkätsvaren kan vi se att rektorerna har en relativt positiv syn på arbetet med IUP. Särskilt positiva är de till arbetslagens roll i arbetet och till den beredskap till förändring som de menar finns på skolorna. I tabellen nedan är de olika aktiviteterna som enkäten tar upp ordnade efter hur rektorerna uppfattar dem - högst upp står de aktiviteter som har fått flest instämmanden i påståendena och därmed också högst medelvärde.

\section{Tabell: Rektorers uppfattning om aktiviteter som rör arbetet med IUP}

$\begin{array}{llccc}\begin{array}{l}\text { Uppfattad } \\ \text { styrkeordning }\end{array} & \text { Aktivitet } & \begin{array}{c}\text { Antal på- } \\ \text { ståenden }\end{array} & \begin{array}{c}\text { Sammanlagt } \\ \text { antal poäng }\end{array} & \begin{array}{c}\text { Medel- } \\ \text { värde }\end{array} \\ 1 & \text { Lärarlag } & 6 & 160 & 26,7 \\ 2 & \text { Beredskap för förändring } & 3 & 77 & 25,7 \\ 3 & \text { Progression } & 5 & 118 & 23,6 \\ 4 & \text { Föräldraengagemang } & 5 & 114 & 22,8 \\ 5 & \text { Utvecklingssamtal } & 7 & 158 & 22,6 \\ 6 & \text { Mentorskap } & 20 & 408 & 20,4 \\ 7 & \text { Elevens reflektion } & 6 & 117 & 19,5 \\ 8 & \text { Lärande } & 8 & 153 & 19,1 \\ & \text { Totalt } & 60 & 1311 & 22,9\end{array}$

Av tabellen framgår det även att rektorerna anser att elevens del i arbetet med IUP fungerar mindre bra. De menar att eleverna ofta är passiva mottagare som inte bidrar med frågor om det egna lärandet och som inte vet hur ökad måluppfyllelse kan nås.

Det här avsnittet fortsätter med en beskrivning av hur rektorerna ser på de olika aktiviteterna. Först presenteras styrkeområdena Lärarlag, Beredskap för förändring och Progression. Därefter följer de områden som ligger runt medelvärdet, nämligen Föräldraengagemang och Utvecklingssamtal, och de områden som vi tolkar som svagheter: Mentorskap, Elevens reflektion och Lärande.

\subsection{Styrkor}

Det som bedömts fungera bäst hör hemma i skolans organisation - det gäller arbetet i lärarlag, det gäller skolans beredskap till förändring, och det gäller det målstyrda arbetet där kursplanerna styr arbetet mot elevernas utvecklingssteg.

\footnotetext{
* Aktiviteterna följer indelningen i Strandberg (2008) men är betecknade något annorlunda. Aktiviteterna finns också beskrivna i avsnitt 2 ovan.
} 


\section{Lärarlag}

Enkäten visar att samtliga skolor är organiserade i arbetslag, där lärarna förbereder utvecklingssamtalen tillsammans och delar på ansvaret för eleverna. Enligt rektorerna blir eleverna uppmärksammade "i många olika lärsituationer", och rektorerna menar också att arbetslagen möjliggör "kreativa kombinationer för elevens träning". Rektorerna är således allmänt positiva till arbetslagens möjligheter att skapa en god bild av elevernas allsidiga utveckling. De är däremot mer tveksamma till arbetslagens funktion att hitta kreativa lösningar för elevers utveckling.

\section{Beredskap för förändring}

Rektorerna är i sina svar positiva till förändringar. De säger sig vara positiva till "kreativa förslag sprungna ur IUP-samtalet", och de svarar att skolan "tycker att det är kul att prova olika kreativa kombinationer för elevens utvecklingssteg". De säger sig också vara beredda på att "IUP-överenskommelser kan betyda modifieringar i organisationen".

Rektorerna verkar således hysa en stark tilltro till att idéer som kommer fram i utvecklingssamtalen tas till vara och att förändringar på organisatorisk nivå vidtas som ett resultat av de åtgärder som tas upp i de individuella utvecklingsplanerna.

\section{Progression}

De fem påståenden som handlar om hur undervisningen styrs mot kunskapsmålen har rektorerna instämt i relativt hög grad i - skolorna har "fördjupat sig i kunskapsmålen", och mentorerna "kan berätta för eleven om kommande utvecklingssteg". Svaren är dock motsägelsefulla. Å ena sidan anser rektorerna att mentorerna är väl insatta i "hur skolan tänker beträffande lärandets progression", men å andra sidan uttalar de sig försiktigt om hur mentorerna känner till "hur respektive ämne utvecklas och vilka målkriterierna är". Nästan hälften av rektorerna ger uttryck för att "skolan inte har fördjupat sig i kursplanernas innehåll eller arbetat fram material som kan konkretisera målen för föräldrar och elever'. Mentorerna bedöms av de flesta rektorerna som professionella. Ändå visar svaren på påståendena om progressionen att rektorerna menar att de kan sakna viktiga kunskaper och förmågor.

\subsection{Områden med utvecklingspotential}

Utvecklingssamtalen och föräldrars och elevers deltagande i dem bedöms fungera tillfredsställande men inte särskilt väl. Dessa områden kan med andra ord beskrivas som områden med utvecklingspotential.

\section{Utvecklingssamtal}

Enligt enkätsvaren har skolorna inte lyckats nå intentionerna för utvecklingssamtalen, nämligen att elever och föräldrar ska bidra till innehållet i samtalen så att de blir något mer än informationstillfällen där skolan informerar om elevens utveckling. Flera rektorer uttrycker en svag tilltro till elevernas förmåga "att träna och vara aktiva i sitt lärande", t.ex. genom att ställa frågor i utvecklingssamtalet. Rektorerna tror inte heller att föräldrarna i så hög grad 
har positiva förhoppningar på sina barn. Däremot hyser alla rektorerna stor eller ganska stor tilltro till sin personals professionalism att veta vad som bör göras i relation till målen i kursplanerna och till deras förmåga att generera goda pedagogiska idéer för att uppnå målen.

\section{Föräldraengagemang}

Föräldrarna verkar ta del av barnens förberedelse inför utvecklingssamtalen, och rektorerna anser i hög grad att föräldrarna "funderar över hur de (på föräldrars vis) kan bidra till måluppfyllelse för sitt barn". Men rektorernas svar antyder att det även finns brister i föräldrarnas engagemang, t.ex. är rektorerna tveksamma till om föräldrarna bidrar till att skapa förväntningar på barnen. Enligt rektorerna vet inte föräldrarna tillräckligt om vilka mål skolan arbetar efter, vilket stämmer med konstaterandet ovan om att skolan inte tillräckligt informerar om dem.

\subsection{Svagheter}

En av de bärande tankarna i användningen av IUP är att eleverna ska få förståelse för sin egen lärandeprocess och motiveras till ett ökat ansvar för sitt lärande. Det är lärarens uppgift att möta eleverna där de är och få dem att tro på sig själva så att de når sina egna mål och de nationella kunskapsmålen. Det är dock elevens reflektion över sitt lärande och lärarens coachning av eleverna som rektorerna bedömt fungera mindre bra.

\section{Mentorskap}

Mentorskap verkar förekomma i någon form på alla de skolor som ingår i undersökningen, och rektorerna markerar att mentorskap är viktigt även om "skillnaden mellan att vara klassföreståndare och att vara mentor" inte verkar vara så tydliggjord. Enligt svaren på vissa frågor är rektorerna relativt övertygade om att mentorerna arbetar som goda coacher och stödjer eleverna att ta nya steg i utvecklingen medan svaren på andra frågor visar att detta inte stämmer särskilt väl. Endast ett par rektorer svarar att deras lärare i utvecklingssamtalet ger uttryck för en hög tilltro till elevens förmåga.

Rektorerna menar att mentorerna oftast ser sin uppgift som spännande och givande, men enkäten visar också att rektorerna inte bistått sina mentorer särskilt väl, t.ex. har inte alla rektorer lyckats fördela mentorsuppgifterna på ett rimligt sätt och de har inte klargjort skillnaden mellan att vara klassföreståndare och mentor.

\section{Lärande}

I påståendena i enkäten används begreppet träningsläger som kan verka främmande i skolans begreppsapparat och bidra till att punkterna under den här rubriken får låga värden. De flesta rektorer menar dock att de har lyckats med att sätta in IUP i ett sammanhang och inte bara ser "dokumentet". De är däremot mer tveksamma till om IUP skapar längtan och lust efter att lära mer hos eleven. Det är ändå ett av huvudsyftena med IUP. Det råder också stor tveksamhet till om skolan tillhandahåller en varierad lärandemiljö vad gäller verktyg och aktiviteter. 


\section{Elevens reflektion}

På de flesta skolor har eleverna "möjlighet att förbereda sig inför IUP-samtal", men enligt rektorerna fungerar inte samtalen så att de stimulerar elevernas reflektion om sitt lärande. Det är inte särskilt vanligt att eleverna själva dokumenterar sitt lärande, vilket skulle kunna vara ett sätt att öka deras reflektion över lärandet. Eleverna har inte heller fått någon skriftlig information om vad en IUP är.

\subsection{Sammanfattning av resultatet}

Sammanfattningsvis visar enkäten till grundskolerektorerna att arbetet med att få fungerande IUP har kommit igång på skolorna. Särskilt nöjda är rektorerna med arbetslagens funktion i arbetet med IUP. Rektorerna menar även att idéer som kommer fram i utvecklingssamtalen leder till förändringar.

Enkäten visar också att det finns en del kvar innan intentionerna i reformen förverkligas.

- Rektorerna hyser en svag tilltro till elevens egen förmåga att bidra till sitt lärande. De tror inte att eleverna är aktiva i arbetet med den individuella planen. Särskilt svag är tilltron till att eleverna dokumenterar och ställer frågor om sitt lärande. Eleverna bedöms således inte reflektera över sitt lärande i särskilt hög utsträckning. IUP bedöms inte heller skapa längtan och lust efter att lära mer hos eleven.

- Rektorerna menar att föräldrarna stöttar sina barn i skolarbetet, men de menar också att det finns brister i föräldrars engagemang. Föräldrarna bedöms inte veta tillräckligt om vilka mål skolan arbetar efter.

- Utvecklingssamtalen har inte blivit de trepartssamtal som är önskvärt utan fungerar framförallt som informationstillfällen, där läraren eller mentorn är informatören och eleverna passiva mottagare till de vuxnas bedömningar.

- Lärare och mentorer har som uppgift att fungera som coacher, men rektorerna litar inte på att lärarna fungerar som det. Rektorerna menar att de skulle kunna stödja dem bättre och fördela mentorsuppgifterna på ett rimligare sätt.

- Skolorna har inte fördjupat sig i kursplanernas innehåll, och de har inte arbetat fram material som kan konkretisera målen för föräldrar och elever. Lärandemiljön på skolorna är inte särskilt varierad avseende verktyg och aktiviteter.

\section{Diskussion och reflektion}

För att få svar på forskningsfrågorna om hur det sociokulturella perspektivet från läroplanen implementerats i grundskolan och hur rektorer ser på arbetet med IUP på sina skolor har vi arbetat med en enkätundersökning till ett antal rektorer i grundskolan. Vi valde att arbeta med en enkät för att på ett enkelt och snabbt sätt få in uppgifter från målgruppen. Vissa frågor i enkäten upplevdes dock som svåra att besvara, och p.g.a. att vi genomförde undersökningen med en enkät kunde vi inte bistå respondenterna med förklaringar, vilket vi kunde ha gjort i en intervjusituation. Vi kunde inte heller ställa uppföljningsfrågor.

För att minska bortfallet av enkätundersökningen valde vi att informera alla rektorer muntligt vid rektorsmöten, och vi påminde vid senare möten. Om man ser till hela populationen, 
som utgörs av samtliga grundskolerektorer i Sverige, är urvalet om 16 rektorer i två mindre kommuner mycket litet och vi kan inte uttala oss särskilt säkert om de slutsatser som dras. Genom svaren på enkätens olika delfrågor har vi ändå kunnat få en bild av hur några rektorer ser på arbetet med IUP och också kunnat skönja hur de ser på sin egen roll i det arbetet.

De frågor som har ställts är konstruerade av Strandberg (2008) och är färgade av hans sociokulturella inriktning och terminologi. Kanske finns där några begrepp som respondenterna inte kände sig bekväma med som coach, träningsläger och utvecklingszoner. Det är värt att kommentera att så få av respondenterna faktiskt utnyttjade det tillägg som gruppen gjorde till svarsalternativen i enkäten, nämligen att man inte har kunskap: 'Känner ej till’. Flera av frågorna skulle förutsätta eller kräva att rektorerna faktiskt hade deltagit som observatörer i utvecklingssamtalen eller på ett systematiskt sätt hade diskuterat med sina medarbetare respektive elever om hur de tänker, vad de förstår och hur de arbetar. Exempel på detta är:

- Mentorn uttrycker i sitt möte med eleven en professionell tilltro till att det är möjligt för eleven att ta ett utvecklingssteg.

- Eleven är duktig på att ge uttryck för sina funderingar.

- Eleven tycker om att lyssna på sin mentor.

Genom uppföljningar riktade till olika parter skulle rektorerna kunna utvärdera vilket utrymme elever och föräldrar får. Det är möjligt att de rektorer som uttalar sig i enkäten grundar sina svar i ett sådant systematiskt kvalitetsarbete, men det ger enkäten ingen kunskap om.

Det vi har fått svar på är några rektorers uppfattning av hur mentorskapet och utvecklingssamtalen fungerar, hur arbetslagen samarbetar, hur progressionen stöds av kursplanemålen, hur elever aktiverar sig i och reflekterar över sitt lärande, hur föräldrar engagerar sig och hur det som kommer i fram i IUP utgör grund för organisatoriska förändringar.

Det är intressant att reflektera över några av de områden som rektor uttalar sig om som svagheter, som faktiskt ligger inom rektors eget handlingsutrymme och ansvar och som rektor således har makt eller mandat att påverka:

- Skillnaden mellan att vara klassföreståndare och att vara mentor är klargjord.

- Arbetslagets fördelning av mentorsuppgifter är rimlig.

- Arbetslaget är organiserat så att lärare arbetar med/har kännedom om lagets samtliga elever.

- Arbetslagstid finns.

- Vår skola har fördjupat sig i kursplanemålen.

- Vår skola har framställt material så att eleverna kan se och förstå kursplanemålen.

- Vi har inte fastnat i dokumenttillverkning utan ser IUP i ett lärandesammanhang.

- Träningslägrets värdegrund är följande attityd: "Hej och välkommen! Du duger och därför kan du ta ett steg till".

- På vår skola är Kan-inte inte en defekt utan en inträdesbiljett till kunskapsutveckling.

- Vi är beredda på att IUP-överenskommelser kan betyda modifieringar i organisationen.

Rektorerna hyser en mycket stark tilltro till arbetslagets funktion som informations- och kommunikationsarena där man lyfter problem och hittar åtgärder. De hyser i allmänhet star- 
kare tilltro till sina lärare än till elever och föräldrar även om man på skolorna inte verkar ha problematiserat lärarnas förändrade roll från att ha varit klassföreståndare till att vara mentor. Mentorsbegreppet är ett resultat av övergången från kvartssamtal till utvecklingssamtal och från regelstyrning till målstyrning. Kvartssamtalet hade en informativ karaktär, och klassföreståndarskapet ingick inte i något lagtänkande.

Man kan fundera över om den ömsesidiga dialogen verkligen kommer till stånd i utvecklingssamtalen och om eleven är en aktiv part. Rektorernas svar antyder ett informationsmöte snarare än en ömsesidig dialog på jämbördiga villkor. En sådan dialog skulle förutsätta någorlunda likvärdiga kunskaper, vilket rektor inte menar finns. Lärare har inte i tillräcklig grad uttolkat målen, föräldrar och elever har inte fått information om målen. Det är också förvånande att rektorerna, som hyser så stark tilltro till sina pedagogers professionalism, inte är helt säkra på att eleverna inte blir passiva mottagare till de vuxnas bedömningar eller vågar beskriva det som kan vara problematiskt eller peppas av sin coach att ge uttryck för egna funderingar. Enligt rektorernas svar har man ännu så länge inte lyckats nå intentionerna för utvecklingssamtalen, nämligen att vara något mer än informationstillfällen.

Rektorerna ger uttryck för att det finns en hög grad av öppenhet, kreativa förslag och modifieringar i organisationen som ett resultat av överenskommelser i IUP. Rektorerna framhåller som en styrka att det som kommer ut av IUP-arbetet påverkar den organisatoriska nivån Det känns överraskande. Det är just det som är kritiken av IUP - att det sällan sätter avtryck på organisationsnivå. Tittar man på hur de individuella utvecklingsplanerna är skrivna utgår de i de flesta fall från elevens svårigheter, och även åtgärderna utgår ifrån de enskilda eleverna. Sällan hittar man skrivningar som är exempel på hur man i stället borde organisera och söka efter andra lösningar i organisationen.

Avslutningsvis kan vi sammanfatta undersökningen som att rektorerna har en positiv syn på IUP, vilket borde vara en förutsättning för ett framgångsrikt arbete, men att det krävs mer för att IUP ska bli ett verktyg för den enskilda individens utveckling och för att vara en del i det systematiska kvalitetsarbetet på organisationsnivå. ${ }^{3}$

\section{Källförteckning}

Förordning (1997:702) om kvalitetsredovisning inom skolväsendet. Hämtad 20091110 på http://www.notisum.se/rnp/sls/lag/19970702.htm

Grundskoleförordningen 1994:1194. Hämtad 20091110 på http://www.notisum.se/rnp/sls/ $\underline{\text { lag/19941194.htm }}$

Hofvendahl J. Arbetsliv i omvandling ( 2006:01 ) Riskabla samtal - en analys av potentiella faror i skolans kvarts- och utvecklingssamtal. Arbetslivsinstitutet.

Högberg, Birgitta (2009) Webbutsändning 31 mars 2009, Skolverket. Hämtad 20091104 på

www.skolverket.se

3 Forskningscirkeln som genomfört enkätundersökningen har bl.a. diskuterat att både medarbetarsamtal och gruppsamtal inom arbetslagen skulle kunna ta sin utgångspunkt i upprättade IUP-dokument. Ett resultat av sådana samtal skulle kunna bli en individuell plan för varje lärare respektive planer för de olika arbetslagen. Dessa planer skulle i sin tur kunna fungera som underlag för kvalitetsarbetet enligt Förordningen om kvalitetsredovisning (1997:702). 
Lpo 94 Läroplan för det obligatoriska skolväsendet, förskoleklassen och fritidshemmet. ISBN 78-91-85545-13-1. Hämtad 20091125 på www.skolverket.se .

Moreau H, Wretman S. Att skriva skriftliga omdömen. Skolverket. Hämtad 20091125 på www.skolverket.se .

Strandberg, Leif (2008) Bland mentorer, IUP och utvecklingszoner. Norstedts Akademiska Förlag. 